\title{
ERRATUM
}

\section{The Osun-Osogbo Grove as a Social Common and an Uncommon Ground: An Analysis of Patrimonial Patronage in Postcolonial Nigeria-ERRATUM}

doi: $10.1017 / S 0940739114000058$

In Akinwumi Ogundiran's article “The Osun-Osogbo Grove as a Social Common and an Uncommon Ground: An Analysis of Patrimonial Patronage in Postcolonial Nigeria," figures 5-7 contained errors. Figure 5 was was placed sideways, and the captions for figures 6 and 7 were switched.

Incorrect copy:

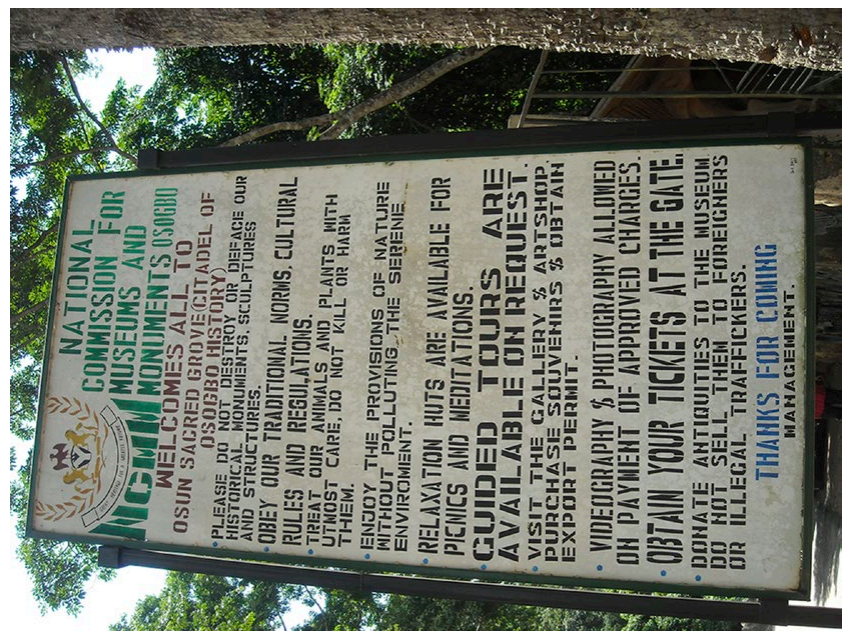

Figure 5. NCMM billboard. 


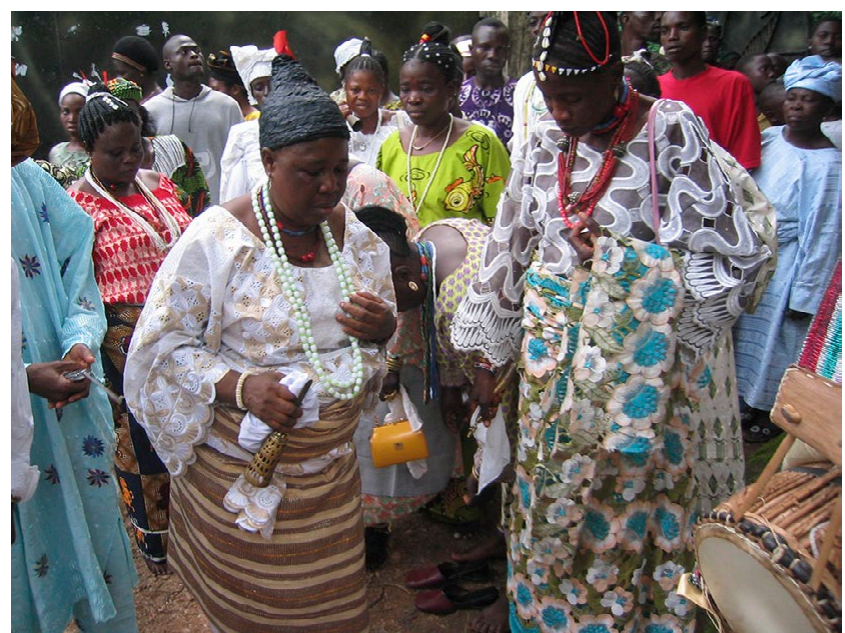

Figure 6. Oba Jimoh Olanipekun, Larooye II (left) and people paying obeisance to the king (right).
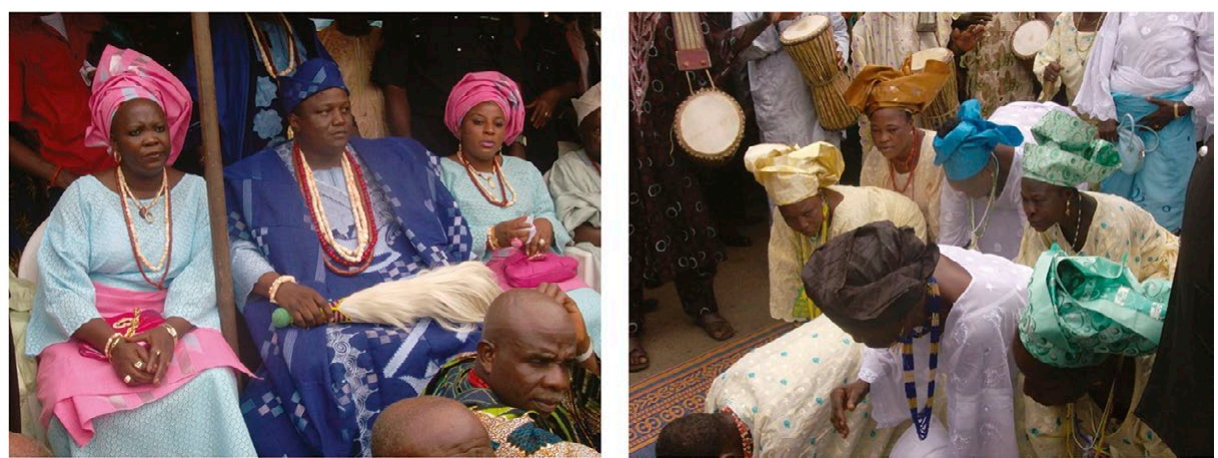

Figure 7. Osun priestesses. 
Correct copy:

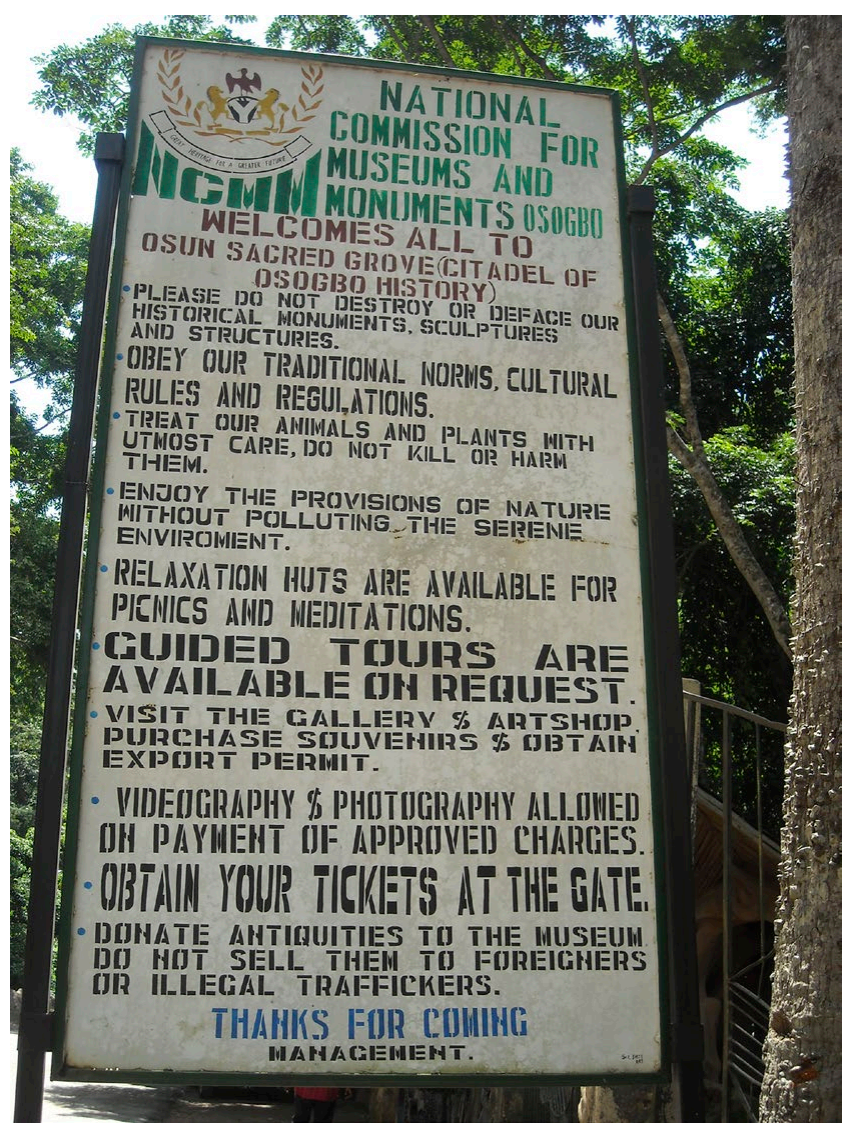

Figure 5. NCMM billboard.

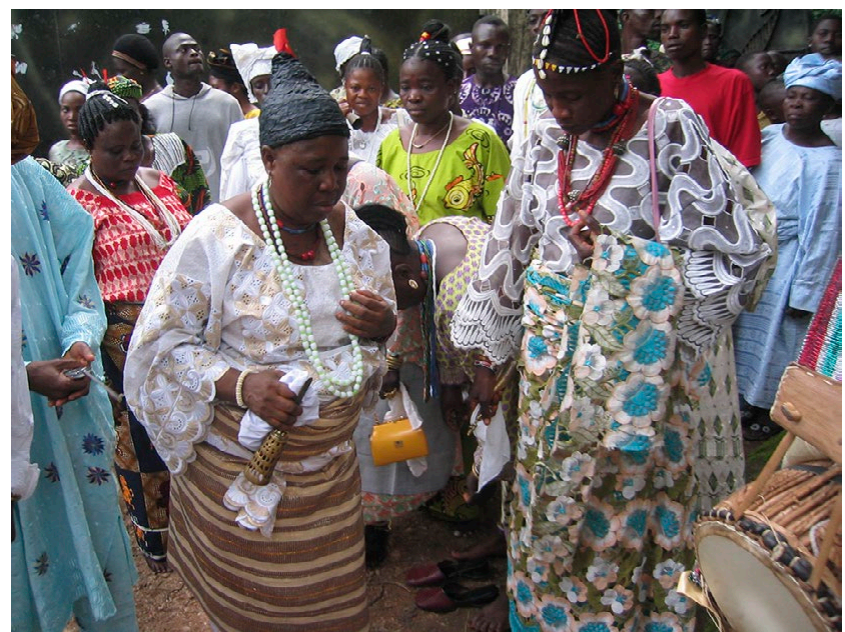

Figure 6. Osun priestesses. 

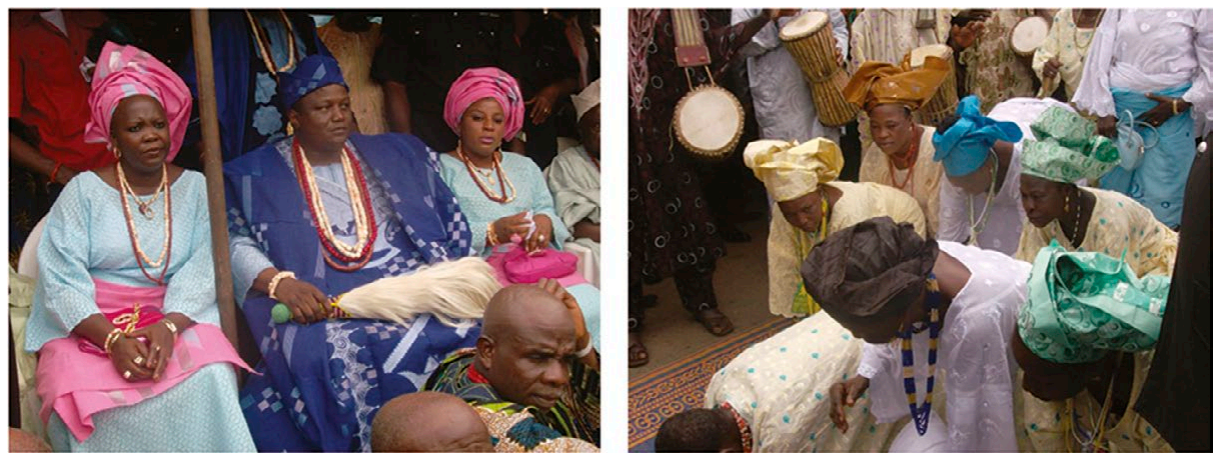

Figure 7. Oba Jimoh Olanipekun, Larooye II (left) and people paying obeisance to the king (right).

The publisher sincerely regrets these errors.

\section{REFERENCE}

Ogundiran, Akinwumi. 2014. "The Osun-Osogbo Grove as a Social Common and an Uncommon Ground: An Analysis of Patrimonial Patronage in Postcolonial Nigeria." International Journal of Cultural Property 21, no. 2: 173-198. 